\title{
A PercepÇÃo de TrabalHadores Terceirizados Sobre as Práticas de Gestão de Pessoasnas Empresas OfFSHORE Da Rede Petro Bacia de Campos
}

\author{
Silvia Cecília Campos Lourenço \\ MestreemAdministraçãoeDesenduimentoEmpresanial \\ pdaUniversidadeEstáciodeSá, CoordanadbradaAgêniade \\ Talentos FaaldadeSalesiana MariaA uxiliadara (Macá́ RJ) \\ silviadareno@igcambr; ageniadkalentos@fsma.edu.br \\ Lamounier Erthal Villela \\ DatoremEconomiaAplicadapdaUnivesitéPanisIII, \\ ProfessardoPrograma deMestradbemA dministração \\ eDesenvivimentoEmpresarial (MADE) da \\ UniversidadeEstáaiodeSá(UNESA) \\ killda@etadabr \\ Jorge Augusto de Sá Brito e Freitas \\ DatoremA dministraçãodeEmpreaspdaPontifía \\ UniversidadeCatdica doRiodeJaniro, Professordo \\ Programa deMestradoemAdministraçãoe elesenvolvimento \\ Empresarial (MADE) daUnivesidadeEstáciodeSá(UNESA). \\ jasbritas@gdbacom jargefritas@estaciabr
}

\section{RESUMO}

E ste artigo identifica a percepção que os trabalhadores que atuam nas empresas offshore da Rede Petro Bacia de Campos têm sobre a adoção de contratos por tempo determinado entre a Petrobras e as empresas prestadoras de serviços. Para a extração das principais conclusões do presente trabalho, empregou-se a análise fatorial exploratória. As respostas obtidas pela aplicação de 169 questionários destacam que 0 contrato firmado entre a Petrobras e suas prestadoras de serviços influencia positivamente a produtividade do trabalho. O s resultados indicam que a preocupação maior dos trabalhadores não está relacionada com os aspectos contratuais da Rede, mas com os benefícios oriundos da adoção, induzida pela Petrobras, de políticas formais de recursos humanos. Tais políticas são capazes de fomentar, nas prestadoras de serviços que compõem a rede, uma sistemática de avaliação de desempenho; de programas de desenvolvimento técnico e comportamental; de compartilhamento de conhecimentos entre os trabalhadores, e um programa de remuneração total (salários e benefícios) consistente com o mercado.

Palavras-chave: Redes E mpresariais. Gestão de Pessoas. Empresas Offshore. Terceirização. Gestão do Conhecimento.

\section{ABSTRACT}

This artideidentifies thepereption that employes who work in offshorecompanies(Pero Baaia deCampos) havea business network on theadqption of fixedttem contrads between Petrobras and companiesthat providethemservices In order toundestand themain condusions of this projet, exploratory factor analysis was utilized Theanswess weredbtained by theapplication of 169 questionnaires that emphasizethecontrad signed between Perdobras and the mentioned companies, and that had a positive ffeet onlabor productivity. Theresults indicatethat themajor conem of workers is not reated to theneworks' contractual aspeets, but to the benfits that wereadqpted by Perdoras, and of theformal pdicies of human resaurcemanagement. Surh pdicies can enhance, within the companies that form this nework, a systematic peformanceealuation; behavioral andtechnical dedepment programs, knoweegesharing amongworkersand a total compensation (salaries andbenfits) program consistengy.

Key words: Business Networks PeepleManagenett. Offshore Companies Outsauring KnowkedgeManagenent. 


\section{INTRODUÇÃO}

Este artigo tem como objetivo identificar a percepção que os funcionários que atuam nas empresas offshore da Rede Petro Bacia de Campos têm sobre a ado ção de contratos por tempo determinado entre a Petrobras e as empresas prestadoras de serviços. Para viabilizar esse objetivo, necessário se faz: a) verificar como os profissionais submetidos a contratos por tempo determinado se pronunciam em relação a essa situação e de que forma suas vidas são influenciadas por esses relacionamentos de trabalho, eb) verificar se as políticas de gestão de pessoas, adotadas pelas empresas offshore da Rede Petro Bacia de Campos, têm visibilidade para os funcionários, mantendo-os motivados e comprometidos.

A suposição central dapesquisa é que o modelo de contratos por tempo determinado estabelecido entre as empresas offshore, prestadoras de serviços da Petrobras e pertencentes à Rede Petro Bacia de Campos, é importante: a) para o relacionamento profissional dos trabalhadores; b) para a motivação e 0 comprometimento deles com a empresa; c) para que as políticas de Recursos Humanos tenham visibilidade para todos, trabalhem eles onshore ou offshore, sendo determinantes para 0 aumento da sua produtividade; $d$ ) para a troca de conhecimentos adquiridos ao longo de sua convivência com os colegas, contribuindo para o desenvolvimento de suas competências profissionais, ee) para a cooperação e o desenvolvimento advindos dos vínculos empregatícios instituídos, potencializando o seu crescimento em nível pessoal e profissional.

As transformações do mundo contemporâneo não são apenas um novo estágio da sociedade industrial, aguçadas pelo rápido avanço tecnológico, mas constituem um salto qualitativo em relação ao período anterior (CASTELLS, 2005). No caso específico objeto deste trabalho, uma forma de fazer avançar as empresas prestadoras de serviços em direção a essa nova realidade foi a sua estruturação em forma de 'rede de empresas' - a Rede PETRO Bacia de Campos - onde os agentes podem discutir, planejar e desenvolver ações de interesse comum.

Essa rede, composta de cerca de 70 empresas terceirizadas - micro, pequenas, médias e grandes - , fornecedoras de serviços para a Petrobras, com tempo médio de vida de cinco a vinte anos, engloba nichos de especialização que agregam valor aos processos da Petrobras - seu nodo central - e, em função desse diferencial, precisa de uma gestão integrada de pessoas em todos os seus nodos, abrangendo os trabalhadores em terra ("onshore") e embarcados ("offshore") em um ambiente de crescimento, motivação e profissionalização, o que permite oxigenar o conhecimento em toda a cadeia de petróleo e gás. A rede faz com que líderes e gestores fiquem mais conscientes do seu papel e das responsabilidades da sua função, o que os fortalece para obter os resultados pactuados entre os diversos nodos, graças ao envolvimento de pessoas motivadas, capacitadas e compromissadas com esse desiderato.

Chanlat (1996) propõe reflexões sobre a necessidade da criação de uma ética das relações quotidianas na gestão de pessoas pelas organizações, em que o papel e o equilíbrio psíquico dessas pessoas sejam considerados e compreendidos dentro da particularidade de cada contexto.
O desconforto com essa perspectiva funcionalista se consolida ao final da década de 90, quando a globalização, o acirramento da competitividade e a aceleração das mudanças clamam pela importância de um repensar da gestão de pessoas, criando um novo quadro de referência que embasa o estabelecimento da Rede Petro Bacia de Campos, objeto principal desta pesquisa.

0 presente artigo se estrutura do seguinte modo: na próxima seção é apresentado o referencial teórico do estudo, constando de uma revisão da literatura sobre os seguintes tópicos: redes de empresas, gestão de pessoas e gestão do conhecimento. Na seção 3 são apresentados os aspectos metodológicos, caracterizando uma pesquisa exploratória, com abordagem quantitativa, usando questionários junto a trabalhadores de cinco empresas pertencentes à Rede Petro Bacia de Campos. Na seção 4, apresentam-se resultados da pesquisa de campo elaborados a partir de uma análise fatorial. Por último, são apresentadas as considerações finais.

\section{REFERENCIAL TEÓRICO}

\subsection{Redes de empresas}

O conceito de rede representa uma quebra de paradigma clássico sobre as organizações. Esse novo conceito suscita mudanças, seja na forma de estrutura organizacional, seja no estilo de gestão, levando a uma nova forma de organização das relações entre as empresas.

\begin{abstract}
Este fenômeno das redes de empresas não é exclusivo das nações desenvolvidas: o mesmo apresenta-se nos países de recente industrialização do sudeste asiático e da América Latina. Com a incerteza econômica persistente nos últimos anos, os níveis de emprego e produção das pequenas e médias estão sendo mantidos e aumentados na medida em que o setor desenvolve uma capacidade de acumulação tecnológica que permite elevar seu desempenho econômico (OLAVE; NETO, 2005, p. 78).
\end{abstract}

Vários autores (JOHNSO N; LUNDVALL, 2005; LASTRE Setal., 2005; MYTELKA; FARINELLI, 2005; PETIT, 2005; SCHMITZ, 2005) têm enfatizado a importância da proximidade geográfica das empresas para explicar um bom desempenho na competitividade de firmas. Alguns termos como economias de aglomeração ("dusteing"), aprendizado por interação, sistemas locais de inovação, eficiência coletiva, estratégias baseadas no conhecimento, exprimem as principais preocupações de tal debate.

Segundo Britto (2002), a Rede Petro BC poderia ser identificada como um processo de subcontratação, terceirização e, em alguns casos, de parceria, realizado por empresas especializadas nas áreas "onshore" e"offshore”, que dão origem a redes estruturadas verticalmente no interior das cadeias produtivas, tendo a Petrobras como principal cliente.

A formação de arranjos e sistemas produtivos locais normalmente é associada a trajetórias de construção de identidades e de formação de vínculos territoriais (regionais e locais), a partir de um contexto social, cultural, político e econômico comum. Sistemas são mais propícios a se desenvolverem em ambientes 
favoráveis à interação, cooperação e confiança entre os atores. Tais vínculos territoriais estão ligados, em sua maioria, à proximidade geográfica, levando ao compartilhamento de visões e valores econômicos, sociais e culturais, constituindo fonte de dinamismo local, bem como de diversidade e vantagens competitivas em relação a outras regiões (RED ESIST, 2005).

A definição que melhor se aplica ao objeto de investigação é a de Lastres e Cassiolato (2003, p. 27), que conceituam os arranjos produtivos locais (APLs) como:

\begin{abstract}
...aglomerados territoriais de agentes econômicos, políticos e sociais - com foco em um conjunto de atividades econômicas - que apresentam vínculos mesmo que incipientes. G eralmente, envolvem a participação e a interação de empresas (...) e suas variadas formas de representação e associação. Incluem também diversas outras instituições públicas e privadas voltadas para: formação e capacitação de recursos humanos (como escolas técnicas e universidades); pesquisa, desenvolvimento e engenharia; política, promoção e financiamento.
\end{abstract}

\subsubsection{Aglomerados, competitividade, cooperação egestão do conhecimento}

Entender as sinergias entre a concentração espacial de atividades produtivas e a própria evolução material da civilização assume especial relevância nos dias atuais, com 0 advento da globalização, pois aponta para o fato de que o surgimento de APLs eficientes e competitivos contribui eficazmente para as inovações.

Um Sistema de Inovação pode ser definido como:

\begin{abstract}
... um conjunto de instituições distintas que, conjuntamente e individualmente, contribuem para o desenvolvimento e a difusão de tecnologias, constituído por elementos e suas relações, onde diferenças básicas em experiências histónicas, culturais e de línguas refletem-se na organização interna da empresa, nas articulações entre elas e outras organizações, nas características sociais, econômicas e políticas do ambiente local, no papel das agências, nas políticas públicas e privadas do setor financeiro, etc. (LASTRES; CASSIOLATO, 2003, p. 24).
\end{abstract}

0 grande desafio é o entendimento dessas relações e interações entre os diferentes agentes, visando ao aprendizado, pois elas apresentam forte especificidade local; e também anecessidade de se ter uma visão específica do território onde se localizam essas médias e pequenas empresas (MPEs). As novas políticas de desenvolvimento industrial e tecnológico devem se direcionar para o fortalecimento da disseminação dessas tecnologias com o objetivo do crescimento e do desenvolvimento das MPEs.

A Rede Petro BC, formada por empresas que prestam serviços para a Petrobras, através de subcontratações, tem também esse desafio de disseminar o conhecimento, através de ações que possam agregar empresas que envolvem até oito níveis de terceirização, para que o capital social adquirido (NAHAPIET; GHOSHAL, 1998) - uma vantagem competitiva com base em ativos intangíveis - não se perca ao longo do tempo.
Cooperar e competir simultaneamente requer mudanças de comportamento, de percepção e de capacitações, resultando na alteração de padrões e indicando a passagem para uma sociedade pós-industrial (BRANDENBURGER; NALEBUFF, 1998; MORGAN, 1996). Quando se pensa em micro e pequenas empresas, são percebidas algumas dificuldades nessa transição, pois as transformações requerem maior capacitação para a compreensão da lógica da mudança. No entanto, as médias e grandes instituições compreendem essas transformações sociais, técnicas e econômicas e conseguem ajustar seus modos de produção.

A organização empresarial e os processos de aprendizado têm como foco:

\begin{abstract}
a empresa vista como uma acumulação de conhecimentos produtivos e, principalmente, como uma entidade capaz de ampliar estes conhecimentos e produzir inovações ...as inovações tecnológicas constituem 0 resultado, o ponto de convergência de uma ampla gama de processos de aprendizado, muitas vezes tratados parcialmente pela literatura - quando são estudados os trabalhos das equipes de P\&D em departamentos formalizados, o leaming by doing ou o leaming by using" (PONDÉ, 2002, p. 299).
\end{abstract}

A ocorrência de múltiplas formas de cooperação produtiva e tecnológica entre empresas que compõem uma rede empresarial tem sido o desafio permanente de uma competitividade com cooperação, em que todos os agentes ganham competências e gerenciam seus conhecimentos.

\subsection{C ustos de transação}

Fiani (2002) apoia-se na teoria dos custos de transação (TCT) para lembrar que ela suspende a hipótese clássica da simetria de informação entre comprador e vendedor, fazendo com que os custos de negociar, de redigir e de garantir o cumprimento de contrato, de estabelecer marcas, de obterinformações sejam significativos na produção empresarial.

Fiani (2002, p. 273) define uma teoria dos contratos, através de quatro diferentes tipos de contratos, estabelecidos entre as organizações:

1. contratos que especificam no presente uma determinada performance no futuro;

2. contratos que especificam no presente uma determinada performance no futuro, condicionada à ocorrência de eventos definidos antecipadamente no futuro, isto é, contratos de cláusulas condicionais;

3. contratos de pouca duração, realizados apenas nos momentos em que as condições necessárias para a realização da transação efetivamente se concretizam, isto é, contratos de curto prazo sequenciais;

4. contratos estabelecidos hoje com o direito de selecionar no futuro uma performance específica dentro do conjunto de performance estipulado previamente, isto é, estabelecer uma relação de autoridade.

Os contratos por tempo determinado realizados entre a Petrobras e seus fornecedores interferem na gestão de pessoas, pois o trabalhador sabe que, ao término do contrato, se não houver renovação, a empresa não poderá mantê-lo em seu quadro de pessoal. 
Diante desse cenário, constatam-se disfunções devidas ao nível de rotatividade dos trabalhadores, levando a dificuldades na gestão de pessoas nas empresas que compõem a Rede Petro Bacia de Campos.

\subsection{Gestão de pessoas}

A questão da subjetividade e complexidade das pessoas que dinamizam a vida organizacional está nas formas de gestão, ou seja, só se pode entender o mundo dos negócios e neleatuar de forma consequente quando se consegue captar a teia das relaçõesinterpessoais nas organizações (DAVEL;VERGARA, 1999).

Essa complexidade leva a discutir a competência profissional, com base em Le Boterf (2003), que afirma a competência do indivíduo ser medida a cada ação; e que o sucesso construído no passado não garante seu futuro. Cada etapa cria uma nova situação, que requeruma avaliação para que comece um novo percurso.

Esse autor identifica seis qualidades que compõem o 'saber administrar':

saber agir com pertinência; saber mobilizar saberes e conhecimentos em um contexto profissional; saber integrar ou combinar saberes múltiplos e heterogêneos; saber transpor; saber aprender e aprender a aprender; saber envolver-se (LE BOTERF, 2003, p. 38).

Dutra (2002, p. 17) caracteriza a gestão de pessoas como "um conjunto de políticas e práticas que permitem a conciliação de expectativas entre a organização e as pessoas para que ambas possam realizá-las ao longo do tempo".

Uma dessas ferramentas é o perfil de competências, que tem como definição: "um conjunto de características pessoais, associado ao processo de atuação, que tem demonstrado causar ou predizer desempenho excelente para uma demanda num determinado ambiente organizacional" (LE BOTERF, 2003, p. 38).

Uma competência é desenvolvida pelo fluxo constante entre mentalidade, prática e tarefa; portanto, mentalidade não é competência. Na verdade, uma competência só se estabelece quando a mentalidade é transformada em comportamento. Da mesma forma, característica não é competência. Uma pessoa pode ser sensível para lidar com diferenças individuais e, no entanto, não aplicar essa sensibilidade no trabalho em equipe. A sensibilidade transforma-se em competência gerencial quando o gestor a usa para conhecer a si e aos outros, bem como para criar, desenvolver e manter equipes de trabalho.

O utro pilar dessa visão vem da evolução do conceito de competência utilizado pelas empresas. Alguns autores dão ao conceito de competência o significado de conjunto de qualificações que a pessoa possui para executar um trabalho com um nível superior de desempenho (SPENCER; SPENCER, 1993; ZWELL, 2000).

Num mercado que se caracteriza pela escassez de postos de trabalho, nele só permanecem os indivíduos que forem capazes de adquirir e desenvolver novos conhecimentos e habilidades, ampliando seu 'portfólio de competências', reconhecendo que os efeitos, em termos de profissionalismo, são o resultado de uma coprodução, ou seja: os empregados não podem ser meros beneficiários da profissionalização: eles são seus atores. É necessário que eles se profissionalizem para que haja profissionalização. Toda aquisição de capacidades, de conhecimentos ou de competências supõe uma atividade de aprendizagem e, portanto, um investimento pessoal (LE BOTERF, 2003, p. 214).

Como parceiros da organização, os empregados são igualmente responsáveis pelo alcance dos resultados desejados. É necessário, portanto, que estejam conscientes das pressões a que a empresa está submetida e assumam a responsabilidade de agregar valor ao trabalho que realizam. Para tanto, é necessário que cada um invista no seu próprio crescimento profissional, adquirindo e desenvolvendo novas competências, sem esperar que essa tarefa seja apenas uma iniciativa da empresa (G O MES et al., 2007; KILIMNIK; SANT'ANNA, 2006; LEITE; PORSSE, 2005).

Com empregados mais qualificados, a empresa poderá enfrentar melhor a concorrência, utilizando o conhecimento disponível para criar novos produtos e serviços. Através da criação e difusão do conhecimento na cultura da empresa, será possível agregá-lo aos processos de trabalho, gerando práticas mais criativas e inovadoras. É por essa razão que muitas empresas estão implantando sistemas de aprendizagem que lhes permitam identificar as competências necessánias à sua força de trabalho e desenvolver atividades de capacitação e desenvolvimento mais focalizadas no negócio da empresa e direcionadas para a produção de resultados.

Para Le Boterf (2003, p. 226),

ainda não existe instrumentação satisfatória para medir globalmente a competência... 0 acompanhamento de indicadores ou de indícios não deve levar à criação de dispositivos e de instrumentos de observação excessivamente sofisticados. Os parâmetros a controlar devem corresponder a algumas variáveis de situações ou de ações julgadas particularmente determinantes.

Trazendo para a realidade da sociedade pós-industrial, 0 conhecimento é considerado o recurso supremo. A capacidade de gerar novos conhecimentos e de agregá-los ao processo produtivo constitui uma vantagem competitiva. Mariotti (1996, p. 52), a respeito dessa vantagem competitiva, lembra que:

A visão da competição como um fim em si é incompatível com a atual abordagem sistêmica e complexa. $\mathrm{Na}$ simples competição, as pessoas atuam umas contra as outras; num ambiente de competência, elas trabalham umas com as outras. Este fato, fácil de mencionar, pode até parecer um simples jogo de palavras. Entretanto, além de difícil de pôr em prática, ele nada tem a ver com o mero falar por falar. Trata-se de uma visão realista e pragmática da condição humana, que faz parte de uma concepção de mundo abrangente.

O desafio consiste em utilizar o conhecimento e as habilidades das pessoas para produzir inovações e alcançar maiores resultados (ALMEIDA et al., 2005). As empresas precisam ser capazes de identificar as competências de que dispõem, e as competências críticas que são demandadas pelos novos proces- 
sos produtivos para desenvolver e gerenciar seus próprios sistemas de desenvolvimento da força de trabalho.

Empresas inovadoras acreditam que a aprendizagem é um processo permanente e que vale a pena criar as condições para que as pessoas possam aprender sempre. Num mundo em permanente mudança, os conhecimentos se tornam rapidamente obsoletos, e muitas qualificações perdem importância, tornando-se descartáveis. A única forma de os trabalhadores se manterem qualificados é através da aprendizagem ativa e contínua, estimulados pela organização de aprendizagem.

Senge (1990) aborda que o aspecto mais sutil da organização de aprendizagem é a nova maneira pela qual os indivíduos veem a si mesmos e ao mundo, pois,

no âmago da organização de aprendizagem está a mudança de mentalidade, a qual implica deixarmos de nos ver separados do mundo para passarmos a nos considerar parte integrante dele, deixarmos de ver nossos problemas como sendo causados por alguém ou alguma coisa 'lá de fora' para compreendermos que eles são causados pelos nossos próprios atos. A organização de aprendizagem é um lugar onde as pessoas aprendem a criar sua própria realidade. E a mudá-la. Como disse Arquimedes: "D ê-me uma alavanca e um ponto de apoio... e moverei o mundo" (SENGE, 1990, p. 22).

Faz parte da cultura das empresas inovadoras o compromisso com o desenvolvimento das pessoas que nela trabalham. Nessas empresas se busca, a partir de uma estratégia claramente definida, criar um espaço em que as pessoas possam estar constantemente envolvidasno processo de criação e difusão de novos conhecimentos e experimentação de novas práticas de trabalho.

LeBoterf (2003, p. 229) destaca a importância da competência coletiva, conceituando-acomo:

\begin{abstract}
... uma resultante que emerge a partir da cooperação e da sinergia existente entre as competências individuais... Com a competência coletiva, certas competências perduram apesar da partida das pessoas. Como as competências são construídas nas interações, os recém-chegados as reconstroem.
\end{abstract}

As empresas inovadoras criam um ambiente em que as pessoas aprendem a compartilhar o resultado de suas experiências e seus achados. Elas constroem uma cultura organizacional que favorece 0 aprendizado coletivo, contribuindo para que a organização atinja maiores níveis de desempenho.

Muito embora a perspectiva de vincular o desenvolvimento de pessoal à melhoria do desempenho não seja nova, 0 ambiente extremamente competitivo no qual as empresas estão operando exige maior focalização em resultados. Por essa razão, muitas delas estão usando a gestão de competências como uma alternativa às abordagens tradicionais de treinamento e desenvolvimento ( $\mathrm{T} \& \mathrm{D}$ ) de recursos humanos. Através das competências, as empresas buscam interligar, de alguma forma, as ações de capacitação ao desempenho e aos objetivos do negócio. As competências agregadas através dos programas de T \& D propiciarão à empresa uma vantagem estratégica, tornando-a mais criativa e inovadora.
Dependendo do contexto, os modelos de competências são construídos a partir da observação e análise do desempenho de pessoas consideradas como excelentes em um determinado tipo de trabalho. Busca-se descobrir o que os melhores estão fazendo e, a partir daí, orienta-se o esforço de capacitação para o desenvolvimento das competências que distinguem os indivíduos de melhor desempenho dos outros. A ação gerencial constitui, portanto, um dos mais importantes suportes à implantação de novas abordagens no trato das questões ligadas à gestão das pessoas nas organizações empresariais.

Para que os modelos de competências aconteçam de forma proativa nas empresas que compõem a Rede Petro BC, os gestores precisam estar preparados para gerenciar pessoas, retendo o conhecimento e fazendo-o oxigenar a organização, trocando e gerando informações dentro da rede, objetivando 0 crescimento tanto do trabalhador quanto da empresa. No entanto, várias são as críticas aos gerentes que, de maneira tradicional, tentam administrar empresas em situações que não se assemelham àquelas do passado. O s tempos atuais requerem mais informações e recursos para o enfrentamento de condições instáveis e inesperadas. O s gerentes, atualmente, são levados a dar respostas a situações complexas que exigem diferentes habilidades. As pressões de tempo, a satisfação do cliente, a redução de custos, entre outras exigências, estão presentes no dia a dia daqueles que administram.

Diante dessas dificuldades e de tanta concorrência no mercado, passa a ser um imperativo para os gerentes conhecer mais profundamente os fatores relacionados ao comportamento humano, como a importância das percepções, a influência das atitudes e a abrangência dos valores. Assim, nas organizações inovadoras, gestores de pessoas são todos aqueles que lideram pessoas, e um de seus maiores desafios é construir um ambiente de aprendizagem. Compete ao líder criar os espaços e os canais para o exercício de construção coletiva de novos conhecimentos e práticas organizacionais. Para tanto, precisa desenvolver novas competências, entre as quais se situa, certamente, a capacidade de estabelecer um diálogo permanente com sua equipe de trabalho. 0 gerente, no papel de educador, tem o desafio de potencializar o desenvolvimento das pessoas.

Nessa era pós-industrial, é cada vez mais enfatizada a importância da disseminação e do compartilhamento do conhecimento entre todos os colaboradores, como citam Goshal e Bartlett (2000, p. 110):
Atualmente, cada vez mais empresas tentam desenvol- ver-se como "especialistas em colaboração". Trata-se de uma característica fundamental para a capacidade da empresa de construir e difundir internacionalmente 0 conhecimento e transformar 0 aprendizado organizacional em fonte de vantagem competitiva.

Se a competência profissional é "administrar uma situação profissional complexa" (LE BOTERF, 2003, p. 37), a gestão de pessoas e de suas relações dependerá, a todo momento, das mudanças de relacionamentos, procurando manter o equilíbrio. 0 ato de liderar pessoas é, e será sempre, complexo e de grande subjetividade, em que todas as partes aprendem e cres- 
cem nessa relação. Nesse âmbito, não existe um modelo único para todas as empresas; não existe sequer um conjunto de melhores práticas adequadas a todas as situações, pois a gestão de pessoas é responsabilidade de todos os líderes e uma responsabilidade última do executivo principal da empresa. Para tanto, pode-se considerar que essa gestão de pessoas é eficaz quando: a) mensura seus resultados; b) posiciona-se estrategicamente; $c$ ) é parceira da linha, e d) não cuida apenas do cotidiano operacional.

Em suma, os líderes precisam repensar a sua atuação como gestores de pessoas e as organizações necessitam muni-los de informações e ferramentas que favoreçam a obtenção de resultados pessoais e organizacionais, com desenvolvimento e envolvimento total das suas equipes.

\subsubsection{A comunicação e o feedback como importantes ferra mentas de gestão}

Lacerda (2005, p. 15) destaca que as maiores barreiras na comunicação eficaz são: a) a filtragem (o emissor filtra informações para torná-las mais palatáveis ao receptor); b) a percepção seletiva (o receptor escuta com base em suas necessidades e motivações); c) a sobrecarga de informação (as pessoas têm uma capacidade finita de processar informações); d) a defesa (diante da ameaça, a tendência é reduzir a capacidade de entendimento mútuo. Assim, quando a comunicação se torna defensiva, existem ataques verbais, comentánios sarcásticos, excesso de julgamento, entre outros comportamentos), e e) a linquagem (0 significado das palavras não está nelas, está em nós e, em função disso, fatores como a idade, a educação e o histórico cultural, influenciam na comunicação eficaz).

Uma das ferramentas de gestão mais eficazes para uma comunicação bem-sucedida é o "feedbadk", pois ele é parte fundamental de um processo que visa orientar as pessoas a apresentarem comportamento e desempenho adequados em uma determinada situação.

Todo o "feelbadk" recebido frequentemente em relação às ações realizadas é de essencial importância para o aprendizado e o crescimento, pois permite que haja uma modificação na maneira de encarar e lidar com determinados assuntos e ideias, e, se necessário, demanda maior empenho em busca de melhores resultados.

Pessoas bem-sucedidas sabem valorizar o "feedbadk" que recebem de seus gerentes, subordinados, clientes, fornecedores no meio em que vivem, e aprendem a utilizá-los em proveito próprio. Essas pessoas, na verdade, até mesmo os buscam. Igualmente reconhecem a necessidade e a importância dessa comunicação, mas o fazem sempre de maneira a aprimorar desempenhos e relacionamentos. A capacidade de criticar construtivamente, de saber receber críticas e utilizálas em proveito próprio é fundamental, não apenas no âmbito do trabalho, mas também nas relações sociais e familiares.

Lacerda (2005, p. 17) define "feedbadk" como sendo:

- toda informação específica referente a um determinado comportamento ou desempenho que encoraja uma pessoa a melhorá-los, reforçá-los ou desenvolvê-los;

- toda informação que leva uma pessoa a tomar consciência de que seu desempenho ou atingiu o padrão desejado, a fim de incentivá-lo e reafirmá-lo, ou ficou abaixo das expectativas, a fim de evitálo e encaminhá-lo em direção ao padrão desejado.

0 que éfundamental nessas definições é que é suposto que as pessoas sejam capazes de apresentar um desempenho adequado ou pretende encaminhá-lo para um padrão mais desejável.

\subsubsection{A motivação e o trabalho}

A motivação tem sido um dos grandes desafios na gestão de pessoas e um dos aspectos mais preocupantes do cotidiano das organizações. São inúmeras as opções para motivar os empregados, há muitos investimentos em novos programas motivacionais e, passado pouco tempo, volta-se à estaca zero. Ao que tudo indica, existe disparidade entre o que se entende por motivação e o que se espera dela na prática, ou seja, o que se pratica so bre motivação nas organizações está distante da discussão e do entendimento conceitual dos estudiosos do assunto.

Por tratar-se de impulso ou necessidade, a motivação é originada basicamente no interior dos indivíduos. Assim sendo, a fala comum de que o chefe tem que motivar seus subordinados, perde seu uso prático, pois sugere algo impossível de se realizar.

Trazendo esse desafio para o gestor, ele deverá sempre procurar identificar os norteadores de comportamento de seus subordinados, levando em conta a natureza intrínseca e individual da motivação, de modo a direcionar a energia que naturalmente se encontra dentro de cada um em sentido compatível com os objetivos da organização e com o crescimento de cadaintegrante no seu grupo de trabalho. Assim, a busca da motivação no trabalho deve estar alinhada com os objetivos organizacionais, utilizando-se as ferramentas eficazes e apropriadas de gestão de pessoas para cada realidade, levadas em conta as peculiaridades da força de trabalho, de modo a contribuir para um ambiente organizacional mais produtivo, saudável e harmônico.

\subsubsection{0 papel da área de Recursos $\mathrm{H}$ umanos na gestão de pessoas}

0 fato significativo dos últimos anos na área de Recursos Humanos é a constatação de que ela só pode contribuir para os resultados da empresa se adotar uma estratégia funcional que seja alinhada com a estratégia maior da organização e que com ela interaja em uma relação biunívoca.

E ssa percepção está em linha com a visão holística, em contraposição à visão funcional, reducionista e departamentalizada da organização. Esse antigo conceito levava a estruturas organizacionais rígidas, pesadas, de pouca flexibilidade, absolutamente incapazes de responder às necessidades de rápida adaptação a mudança que os dias de hoje exigem.

Boog (1994, p. 108) lembra que:

É preciso que todos os colaboradores saibam qual é o
ponto para onde devem orientar-se a fim de que re-
mem na mesma direção, permitindo a visualização do
norte da organização, estabelecendo estratégias de cur-
to, médio e longo prazo, baseadas na interação de todos
os agentes que intervêm: aspectos mercadológicos,
tecnológicos, financeiros, de relações com a comunida-
de etc. Essas informações precisarão ser perpassadas 
pela contribuição esperada das pessoas da organização, uma vez que serão elas que acionarão todos esses aspectos e darão vida a essa estratégia.

A estratégia de gestão de pessoas não somente deve fazer parte da estratégia global da organização, mas deve constituir-se no canal fundamental para que as empresas se transformem em ambientes sadios e motivadores, objetivando a realização pessoal e profissional de seus colaboradores. Nos dias atuais, isso não pode ser conseguido sem que o conhecimento organizacional ocupe lugar de primazia nas preocupações empresariais.

\subsection{Gestão do conhecimento}

Goshal e Bartlett (2000, p. 76) conduzem a uma reflexão inicial sobre o compartilhamento histórico das informações dos antepassados, lembrando que:

Durante milhares de anos, as famílias, os clãs e as comunidades evoluíram como grupos docentes e discentes, com as pessoas compartilhando as informações e sintetizando conhecimentos, como elemento central dos vínculos do intercâmbio social e força motriz primordial do progresso coletivo. No entanto, de alguma forma, as empresas modernas se desenvolveram segundo um modelo que constrange, inibe e às vezes aniquila esse instinto natural nas pessoas.

Porém, diante desse novo cenário empresarial, essa postura de inibição e aniquilação do conhecimento precisa ser revista, dentro de uma nova visão estratégica de recursos humanos, que nos conduz para um gerenciamento cujo conhecimento se tornou um elemento fundamental e imprescindível ao sucesso da empresa. Contudo, a oferta excessiva de informações e conhecimentos no mercado em relação à demanda dificulta sua manipulação e seu uso, levando as pessoas a acessá-los a partir da perspectiva de alguém que os filtra.

Rossatto (2003, p. VIII), a respeito desse assunto, alerta:

Esse filtro pode deturpar o verdadeiro sentido, pois resulta da interpretação de alguém. Interpretações diferentes podem levar a conhecimentos distintos e contraditórios. Além disso, o conhecimento está em constante transformação, pois depende da forma de comunicação adotada pelo transmissor para enviá-lo até 0 receptor. Tudo isso, associado a outros fatores, pode prejudicar a difusão e o uso do conhecimento na empresa. Assim, considerando que o conhecimento é a chave do poder nos negócios, deve-se geri-lo de modo a transformá-lo em valor e a trazer vantagem competitiva para a organização. Para tanto, as empresas precisam direcionar seus processos de negócios para a gestão do conhecimento.

A gestão do conhecimento deve auxiliar a empresa a cumprir sua estratégia com excelência em todas as suas áreas de negócios. Nesse contexto, auxilia os processos de tomada de decisão estratégica, incorpora uma postura estratégica à empresa, e permite conhecer melhor sua situação competitiva no mercado.

Diante disso, a gestão do conhecimento deve direcionar o uso do conhecimento para a criação de inovações que gerem valor para os clientes e tragam vantagem competitiva para a empresa. Enxergado sob esse ângulo, o conhecimento, apesar de ser um ativo intangível, pode originar produtos e serviços tangíveis. Stewart (1998, p. 89) afirma que em "uma empresa voltada para o conhecimento [...] não só os principais ativos [...] são intangíveis como também não está claro quem os possui ou quem é responsável por cuidar deles".

O capital intelectual é uma das vertentes da gestão do conhecimento e ele deve ser conduzido de forma estratégica pela área de Recursos Humanos, com o apoio de todos os gestores, em um caminho para a busca, o reconhecimento ea manutenção de talentos dentro da organização. Embora haja certa superposição conceitual entre a gestão do conhecimento e o capital intelectual (CHO O ; BO NTIS, 2002), pode-se considerar que o capital intelectual representa 0 'estoque' de conhecimento que existe na organização em dado momento, ou seja, 0 que a organização aprendeu. Gerenciar esse estoque de conhecimento na empresa para que ele flua e cresça é o domínio da gestão do conhecimento.

\section{ASPECTOSMETODOLÓGICOS}

A pesquisa desenvolvida é exploratória e usou abordagem quantitativa, tendo como universo as empresas offshore da cadeia de petróleo e gás, prestadoras de serviços da Petrobras e pertencentes à Rede Petro Bacia de Campos, situadas no município de Macaé.

O s passos necessários à pesquisa de campo foram:

1) O btenção de autorização da Secretaria Executiva da Rede Petro Bacia de Campos para pesquisar a rede e algumas empresas que a compõem.

2) Indicação, por parte da rede, de empresas de médio e grande porte a ela associadas, para que fosse efetuada a coleta de dados.

3) Levantamento dos dados para estudo, através da aplicação do questionánio. D as 70 (setenta) empresas da Rede Petro BC - micro, pequenas, médias e grandes -, foram indicadas cinco empresas: uma de grande porte e quatro de médio porte, identificadas mais abaixo. Foi entregue um total de 200 (duzentos) questionários em envelopes lacrados individualmente, em mãos, aos responsáveis pelas áreas de RH das empresas, com data agendada para entrega, e foram recebidos, ao final do processo, 169 (cento e sessenta e nove), preenchidos e devidamente lacrados. Foi adotado um critério de escolha aleatória dos respondentes, gerada a partir de seu número de matrícula na empresa. Um problema encontrado foi o preenchimento dos questionários pelo pessoal offshore, pois nem sempre passam pela sede da empresa nem embarcam a partir de um só local. $\mathrm{D}$ a mesma forma, como os questionários foram enviados lacrados e nominais, as respostas só foram recebidas quando uma equipe desembarcava e um portador tinha disponibilidade de entregá-los na sede da empresa.

4) Tratamento dos dados, através da análise fatorial, cujos resultados mais significativos aparecem na próxima seção. 
As cinco empresas que participaram da pesquisa, com autorização prévia dos responsáveis pelaárea de $\mathrm{RH}$, foram: Techint S.A., empresa de grande porte, com 350 empregados onshore e 1.000 offshore; Petrometal Engenharia Ltda, empresa de médio porte, com 263 empregados onshore e 65 offshore; Weatherford Indústria e Comércio Ltda., empresa de grande porte no mundo e de médio porte em Macaé/ RJ, com 160 empregados onshore e 73 offshore; Sparrows BSM Engenharia Ltda., empresa de médio porte, com 35 empregados onshore e 175 offshore; Q \&B Serviços Ltda., empresa de médio porte, com 170 empregados onshore e 320 offshore que fazem parte da Rede Petro Bacia de Campos.

O levantamento, feito através de questionário, foi respondido por 40 (quarenta) colaboradores de cada uma dessas empresas, sendo 20 (vinte) onshore e 20 (vinte) offshore, totalizando 200 trabalhadores, versando sobre a importância da adoção de contratos por tempo determinado no relacionamento dos funcionários das empresas offshore contratadas pela Petrobras que fazem parte da Rede Petro Bacia deCampos.

$\mathrm{O}$ instrumento para coleta de dados foi um questionário estruturado e autoadministrado, com escala tipo Likert de cinco opções de resposta (Concordo totalmente; Concordo; Não concordo nem discordo; D iscordo, Discordo Totalmente). 0 questionário foi composto de 20 itens, além de cinco questões sobre identificação do respondente, conforme abaixo descrito:

01) Acho que meu trabalho é avaliado com justiça.

02) Meu supervisor comunica-me periodicamente suas opiniões sobre meu trabalho.

03) Existem boas chances de promoção nessa empresa.

04) Possuo informações suficientes para fazer bem o meu trabalho.

05) A empresa geralmente promove o seu pessoal qualificado antes de buscar gente de fora.

06) 0 treinamento que tenho recebido tem sido adequado para o trabalho que faço.

07) A minha empresa se preocupa em treinar-me para exercer outras funções, preocupada com a minha realocação interna, caso o seu contrato com a Petrobras seja encerrado.

08) Participo sempre de treinamentos comportamentais para melhoria das relações com meus colegas de trabalho.

09) Considero que a empresa se preocupa com a retenção do conhecimento de seus funcionários e os valoriza para não perdê-los para as concorrentes.

10) Considero que sou muito bem pago pelo trabalho que faço.

11) Considero que a empresa procura manter os salários de acordo com o mercado.

12) A empresa concede aumentos, gratificações e participação nos resultados elucros.

13) Os benefícios que recebo na empresa atendem às minhas necessidades.

14) Considero que a carga horária de trabalho imposta pela empresa é justa.
15) Em minha opinião, a escala de embarque/ desembarque para os funcionários offshore atende às minhas necessidades.

16) A minha empresa se preocupa com a minha qualidade de vida.

17) Em minha opinião, os contratos por prazos determinados realizados entre a minha empresa ea Petrobras não interferem no meu desempenho.

18) Em minha opinião, caso o contrato por tempo determinado da minha empresa com a Petrobras não seja renovado, serei reaproveitado internamente em outras funções.

19) Acredito que os contratos firmados entre a minha empresa e a Petrobras influenciam positivamente na produtividade do meu trabalho.

20) Considero-me um funcionário motivado e comprometido com o meu futuro na minha empresa.

D ados do entrevistado: local de trabalho; sexo; nível de escolaridade; tempo de experiência na função atual; e tempo na empresa.

A investigação também se valeu de documentos internos da Rede Petro BC (trabalhos preliminares realizados por instituições públicas e privadas quando da constituição da rede, documentos da D iretoria com diretrizes sobre as ações realizadas, etc.) que dizem respeito aos contratos por tempo determinado e a gestão de pessoas nas empresas offshore que compõem a rede. $O$ site da Rede Petro Bacia de Campos (www.redepetrobc.com.br) foi utilizado para coleta de informações sobre as visitas técnicas, novas empresas associadas e detalhamento das organizações parceiras. Tais documentos foram utilizados para a contextualização da Rede Petro Bacia de Campos e para a elaboração dos questionários da pesquisa de campo. No tocante à extração das variáveis para a elaboração do questionário, os documentos foram submetidos a uma análise de seu conteúdo, no sentido genérico atribuído por Patton (2002, p. 453): "qualquer esforço de... inteligibilidade ("sense-making") que se aplica a dado volume de material qualitativo para tentar identificar consistências e significados essenciais". D aí surgiram categorias temáticas (BOYATZIS, 1998) que originaram as proposições do questionánio, composto de 20 itens, acima elencados.

Os itens do questionário foram tratados por análise fatorial, que segundo Hair et al. (1998), ao sintetizar os dados, a análise fatorial deriva dimensões fundamentais que, quando compreendidas e interpretadas, descrevem os dados em um número muito menor de construtos do que as variáveis individuais originais.

\section{RESULTADOSDA PESQ UISA}

Neste estudo, a análise permite extrair quatro fatores mais significativos na relação dos contratos por tempo determinado realizados entre a Petrobras e as empresas offshore sendo que dois são mais importantes, já que estão relacionados às políticas de RH e às relações contratuais, respectivamente, mostrados na Tabela 1. 
Tabela 1: Matriz de principais fatores com itens do questionário

\begin{tabular}{|c|c|c|}
\hline Itens do Q uestionário & 1 Políticas de RH & $\begin{array}{l}2 \text { Relações } \\
\text { Contratuais }\end{array}$ \\
\hline VA) Acho que meu trabalho é avaliado com justiça & ,693 & 117 \\
\hline VC) Existem boas chances de promoção na minha empresa & ,612 &,- 025 \\
\hline $\begin{array}{l}\text { VE) A empresa geralmente promove o seu pessoal qualificado antes de buscar gente } \\
\text { de fora }\end{array}$ & ,619 & 167 \\
\hline $\begin{array}{l}\text { VI) Considero que a empresa se preocupa com a retenção do conhecimento de seus } \\
\text { funcionários e os valoriza para não perdê-los para as concorrentes }\end{array}$ & ,794 & ,087 \\
\hline VJ) Considero que sou muito bem pago pelo trabalho que faço & 739 & 059 \\
\hline VK) Considero que a empresa procura manter os salários de acordo com o mercado & ,691 & 027 \\
\hline VM) Os benefícios que recebo na empresa atendem às minhas necessidades &, 551 & 155 \\
\hline $\begin{array}{l}\text { VO) Em minha opinião, a escala de embarque/ desembarque para os funcionários } \\
\text { dffhreatende às minhas necessidades }\end{array}$ & ,166 & ,600 \\
\hline $\begin{array}{l}\text { VR) E m minha opinião, caso o contrato por tempo determinado da minha empresa } \\
\text { com a Petrobras não seja renovado, serei reaproveitado internamente em outras } \\
\text { funções }\end{array}$ & ,246 & ,747 \\
\hline $\begin{array}{l}\text { VS) A credito que o contrato firmado entre a minha empresa e a Petrobras } \\
\text { influencia positivamente na produtividade do meu trabalho }\end{array}$ & ,004 & ,725 \\
\hline $\begin{array}{l}\text { VT) Considero-me um funcionário motivado e comprometido com o meu futuro na } \\
\text { minha empresa }\end{array}$ & ,526 & 239, \\
\hline
\end{tabular}

Fonte: Elaborada pelos autores.

Dependendo da aplicação objetivada pela análise fatorial, 0 pesquisador pode se sentir satisfeito com a interpretação dos fatores ou pode continuar aplicando outras técnicas estatísticas. Na medida em que se desejava tão somente identificar as combinações lógicas das variáveis e uma compreensão melhor das interrelações entre variáveis, julgou-se suficiente que fossem identificados os fatores 'Políticas de RH', com oito variáveis; e 'Relações Contratuais', com três variáveis. (HAIR et al., 1998). As variáveis componentes de cada fator encontram-se em negrito na Tabela 1.

Remetendo aos dados da Tabela 1, o teste de esfericidade de Bartlett verificou a presença de comelação entre variáveis, apresentando a probabilidade estatística de que a matriz de correlação apresentasse correlações significativas entre, pelo menos, algumas dessas variáveis. Isso se confirma pela medida de adequação da amostra de Kaiser-Meyer-O lkin (KMO ), que alcançou 0,773, medida considerada razoável (acima de 0,7) e bem próxima de 'meritória' (acima de 0,8).

Assim, os resultados sugerem que o contrato firmado entre a Petrobras e suas empresas prestadoras de serviços influencia positivamente na produtividade dos trabalhadores. A preocupação maior dos trabalhadores não está relacionada a aspectos diretamente decorrentes da modalidade específica de contrato, mas aos procedimentos de gestão de pessoas aplicados através de políticas convencionais de recursos humanos.
Destacam-se, nos próximos parágrafos, os resultados mais significativos. Assim, a proposição da variável I: 'Considero que a empresa se preocupa com a retenção do conhecimento de seus funcionários e os valoriza para não perdê-los para as concorrentes' remete à importância de modelos mais sistêmicos, baseados na valorização do conhecimento e das informações, ponto destacado por Villela (2005), como característico das novas formas de organização de trabalho nas relações pós-industriais. 0 escore encontrado - de 0,794 , bastante alto - não condiz com a realidade das relações entre os profissionais que trabalham nas empresas offshore, pois o compartilhamento de conhecimentos que contribui para o desenvolvimento de suas competências profissionais é dificultado pela forma desorganizada e descomprometida da migração de pessoal entre prestadoras de serviços da Petrobras. Com isso, prevalecem as ações imediatistas, sem que haja suficiente preocupação com 0 desenvolvimento das competências dos profissionais.

Considerando os efeitos indesejáveis da migração apontada, entre os quais avulta a despreocupação dos trabalhadores com a autogestão de sua carreira e o desenvolvimento de suas competências, foi constatado que um dos motivos desse comportamento estáligado à afirmativa (variável L): 'Considero que sou muito bem pago pelo trabalho que faço', que obteve um resultado de discordância significativo; porém, ao se comparar 
com a afirmativa (variável $\mathrm{K}$ ): 'Considero que a empresa procura manter os salários de acordo com o mercado', constata-se um índice menor, levando a concluir que, na opinião do trabalhador, a problemática está mais relacionada ao sentimento de insuficiente retribuição pelas peculiaridades e dificuldades do trabalho em regime de revezamento no offshore do que uma sensação generalizada de remuneração inferior ao mercado de trabalho.

Para melhor entender 0 ambiente relacionado à remuneração total (salários mais benefícios), faz-se necessária uma análise da afirmativa (variável M): 'O s benefícios que recebo na empresa atendem às minhas necessidades', cujo resultado demonstra a preocupação das empresas em oferecer um pacote de benefícios mais atraentes do que os salários, já que precisam assegurar o bem-estar dos empregados e seus dependentes, em especial dos colaboradores offshore, que ficam ausentes do lar por durante 15 dias, necessitando de mais tranquilidade para desempenhar suas funções a contento.

Contrabalançando 0 exposto acima, a afirmativa (variável T): 'Considero-me um funcionário motivado e comprometido com o futuro na minha empresa' leva ao entendimento de que, apesar das restrições que fazem aos salários e das disfunções que a migração dos trabalhadores entre as empresas offshore no âmbito da rede estudada, os funcionários se sentem motivados e acreditam no seu futuro nas empresas.

\section{CONSIDERAÇÕESFINAIS}

As respostas obtidas destacam que a percepção dos trabalhadores sobre os contratos por tempo determinado firmado entre a Petrobras e as empresas prestadoras de serviços, no âmbito da Rede Petro Bacia de Campos, influencia positivamente a produtividade laboral. A pesquisa indicou que a maior preocupação dos trabalhadores não está diretamente relacionada a aspectos decorrentes da modalidade de relação contratual entre a Petrobras e as empresas prestadoras de serviço, mas, sim, pela "regulação" da Petrobras quanto à gestão de pessoas das empresas terceirizadas.

A política de recursos humanos da rede tem se mostrado, pela percepção dos respondentes da pesquisa, capazes de gerar um ambiente sadio e motivador. O s mesmos consideram relevantes os seguintes aspectos de tais políticas: avaliação de desempenho justa, programas de treinamento comportamental para a melhoria nas relações com colegas e supervisores, ênfase na troca de conhecimentos com colegas que contribuam para o desenvolvimento de suas competências profissionais, além de salários e benefícios em linha com o mercado.

A troca de conhecimentos entre os trabalhadores da rede deve contribuir para o desenvolvimento de suas competências profissionais e ser direcionada para agregar valor aos produtose serviços das empresas constituídas na rede. D essa forma, os conhecimentos ampliam as vantagens competitivas para a Rede Petro Bacia de Campos como um todo. Visto por outra ótica, a rede Petro é formadora de um "capital intelectual" que deve ser priorizado estrategicamente, tanto pela govemança da rede como pelaárea de RH de cada empresa.

Conclui-se que quanto mais as empresas da Rede Petro estiverem conscientes sobre a importância da troca de informa- ções, naidentificação de demandas, na elaboração de políticas de $\mathrm{RH}$, melhores poderão ser seus resultados na gestão de pessoas. Portanto, o grande desafio da Rede Petro Bacia de Campos é de ser a articuladora desse ambiente, fortalecendo os laços entre os agentes envolvidos nesse contexto, a fim de obter uma melhoria nas relações entre os trabalhadores, as empresas e a Petrobras. Tal articulação ou governança da rede deve fomentar uma gestão de pessoas voltada aos interesses legítimos de todos os envolvidos, tendo como frutos a cooperação e o desenvolvimento, advindos dos vínculos empregatícios instituídos, que potencializam o crescimento pessoal e profissional.

\section{REFERÊNCIAS}

ALMEIDA, P.; PHENE, A.; GRANT, R. Innovation and knowledge management: scanning, sourcing, and integration. In: EASTERBYSMITH, M.; LYLES, M. A. (ed.). The Bladkwell handbook of organizational learning and knouledge management. O xford, UK: Blackwell, 2005, p. 356-371.

BO O G, G. Manual detrenamento edesenvdvimenta São Paulo: Makron Books, 1994.

BOYATZIS, R. E. Transforming qualitative information: thematic analysis and code development. Thousand Oaks, CA: Sage, 1998.

BRANDENBURGER, A. M.; NALEBUFF, B. J. Co-queition. New York: Currency D oubleday, 1998.

BRITTO, J. N. P. Diversificação, competências e coerência produtiva. In: KUPFER, D.; HASENCLEVER, L. (org.). Economia indus trial: fundamentos teóricos e práticos no Brasil. Rio de Janeiro: Campus, 2002.

CASTELLS, M. A sociedade emrede São Paulo: Paz e Terra, 2005.

CHANLAT, J.-F. Por uma antropologia da condição humana nas organizações. In: CHANLAT, J.-F. (coord.). O indivíduo na arganiza ção dimensões esquecidas. 3. ed. São Paulo: Atlas, 1996.

CHO O, C. W.; BONTIS, N. The strategic management of intellectual capital and arganizational knowkedge New York: Oxford University Press, 2002.

DAVEL, E.; VERGARA, S. C. (org.). Gestão compesscas esubjeividade São Paulo: Atlas, 2001.

DUTRA, J. S. Gestão de pesscas São Paulo: A tlas, 2002.

FIANI, R. Teoria dos custos de transação. In: KUPFER, D; HASENCLEVER, L. (org.). Economia industrial: fundamentos teóricos e práticos no Brasil. Rio de Janeiro: Campus, 2002.

GOMES, C. E. et al. Competências organizacionais e individuais: 0 que são e como se desenvolvem. In: HANASHIRO, D. M. M.; TEIXEIRA, M. L. M.; ZACCARELLI, L. M. (org.). Gestão do fator humana uma visão baseada em stakeholders. São Paulo: Saraiva, 2007, p. 215-255.

GO SHAL, S., BARTLETT, C. A empresa individualizada: talento e atitude como vantagem competitiva. Rio de Janeiro: Campus, 2000.

G PI-COPPE/ UFRJ. Relatónio do Projeto de Estruturação da Rede de Empresas do Setar dePetróleo da Bacia de Campos Rede Petro BC, Rio de Janeiro, 2003.

HAIR et al. Multivariate data analysis. New Jersey: Prentice Hall, 1998.

JOHNSO N, B.; LUNDVALL, B.-A. Promovendo sistemas de inovação como resposta à economia do aprendizado crescentemente globalizada. In: LASTRES, H. M. M.; CASSIOLATO, J. E.; ARROIO, A. (org.). Conheimento sistemas de inovação e desenvdvimenta Rio de Janeiro: UFRJ/ Contraponto, 2005, p. 83-130. 
KILIMNIK, Z. M.; SANT'ANNA， A. S. Modernidade organizacional, política de gestão de pessoas e competências profissionais. In: BO RG ES-AND RAD E, J. E.; ABBAD, G. S.; MO URÃO, L. (org.). Treinamento, Desenvdvimento e Educação em Organizaçaes e Trabalho fundamentos para a gestão de pessoas. Porto Alegre: Bookman Artmed, 2006, p. 85-96.

KUPFER, D.; HASENCLEVER, L. (org.). Economia Industrial: fundamentos teóricos e práticos no Brasil. Rio de Janeiro: Campus, 2002.

LACERDA, M. C. Programa Gestão de Negóios com Pesscas para o E\&P. Belo Horizonte: Fundação D om Cabral, 2005.

LASTRES, H. M. M.; CASSIOLATO, J. E. In: LASTRES, H. M. M.; CASSIO LATO, J. E.; MACIEL, M. L. PequenaEmpresa: cooperação e desenvolvimento local. Rio de Janeiro: Relume D umará, 2003.

; ARRO IO, A. Sistemas de inovação e desenvolvimento: mitos e realidade da economia do conhecimento global. In: LASTRES, H. M. M.; CASSIOLATO, J. E.; ARROIO, A. (org.) Conheimento Sistemas de Inovação e Desenduimenta Rio de Janeiro: UFRJ/ Contraponto, 2005, p. 17-50.

Le BOTERF, G. Desenvdvendo a Competênia dos Profissionais 3. ed. rev. ampl. Porto Alegre: Bookman, 2003.

LEITE, J. B. D.; PO RSSE, M. C. S. Competição baseada em competências e aprendizagem organizacional: em busca da vantagem competitiva. In: RUAS, R.; ANTONELLO, C. S.; BOFF, L. H. (org.) Aprendizagem Organizacianal e Competênias. Porto Alegre: Bookman, 2005.

MARIO TTI, H. Organizacães deAprendizagem São Paulo: A tlas, 1996. MO RGAN, G. Imagens da Organizaçãa São Paulo: Atlas, 1996.

MYTELKA, L.; FARINELLI, F. D e aglomerados locais a sistemas de inovação. In; LASTRES, H. M. M.; CASSIOLATO, J. E.; ARRO IO, A. (org.). Conheimento Sistemas de Inovação e Desenvdvimenta Rio de Janeiro: UFRJ/ Contraponto, 2005, p. 347-378.

NAHAPIET, J.; GHOSHAL, S. Social capital, intellectual capital and the organizational advantage. Acadamy of Management Review, v. 23, n. 2, p. 242-266, 1998.

OLAVE, M. E. L.; NETO, J. A. A formação de redes de cooperação e clusters em países emergentes: uma alternativa para PMEs no Brasil. In: NETO, J. A. (org.). Reedes entre Organizaçoes: domínio do conhecimento e da eficácia operacional. São Paulo: Atlas, 2005.

PATTON, M. Q. Qualitative Research \& Evaluation Methods. 3. ed. Thousand Oaks, CA: Sage, 2002.

PETIT, P. Estrutura e desenvolvimento de uma economia baseada no conhecimento: implicações para políticas. In: LASTRES, H. M. M.; CASSIO LATO, J. E.; ARRO IO, A. (org.). Conheeimento Sistemas de Inovação e Desenvdvimenta Rio de Janeiro: UFRJ/ Contraponto, 2005, p. 131-160.

PO NDÉ, J. L. Organização das grandes corporações, In: KUPFER, D.; HASENCLEVER, L. (org.). Econamia industrial: fundamentos teóricos e práticos no Brasil. Rio de Janeiro: Campus, 2002.

REDE PETRO BC: Rio de Janeiro, 2005. Disponível em: <http:/ / redepetro-bc.com.br>

RED ESIST. D isponível em: <http:/ / www.redesist.ie.ufrj.br. A cesso em 07/ 11/ 2006.

ROSSATT 0, M. A. Gestão do conhedimento. Rio de Janeiro: Interciência, 2003.

SCHMITZ, H. Aglomerações Produtivas Locais e Cadeias de Valor: como a organização das relações entre empresas influencia o aprimoramento produtivo. In: LASTRES, H. M. M.; CASSIO LATO, J. E.;
ARRO IO, A. (org.). Conheimento sistemas deinovação edesenvdvimento Rio de Janeiro: UFRJ/ Contraponto, 2005, p. 321-346.

SEBRAE. D isponível em: <http:/ / www.sebrae.com.br> Acesso em: 11 jul. 2006.

SENG E, P. M. A quinta disciplina São Paulo: Best Seller, 1990.

SPENCER, L. M.; SPENCER, S. M. Competenceat work: models for superior performance.

New York: Wiley, 1993.

STEWART, T. Capital inteletual: a nova vantagem competitiva das empresas. Rio de Janeiro: Campus, 1998.

VILLE LA, L. E. Estratégias de cooperação e competição de organizações em rede - uma realidade pós-fordista? In: ENCONTRO NACIONAL DA ASSO CIOÇÃO NACIONAL DO S PROGRAMAS DE PÓ S-G RADUAÇÃO EM AD MINISTRAÇÃO, 29, 2005, Brasilia. Anais.. Brasília: ANPAD, 2005. CD - ROM.

ZWELL, M. Creating alture of comptence New York: Wiley, 2000.

Data de Submissão: 01/ 07/ 2008

D ata de Aprovação: 23/ 03/ 2010 
